\title{
Hysterical Representation in the Art of Mary Sibande
}

\section{Anne Scheffer}

Department of Fine and Applied Arts, Tshwane University of Technology archera@tut.ac.za

\section{Ingrid Stevens}

Department of Fine and Applied Arts, Tshwane University of Technology stevensie@tut.ac.za

\author{
Amanda du Preez \\ Department of Visual Arts, \\ University of Pretoria \\ amanda.dupreez@up.ac.za
}

\begin{abstract}
The character, Sophie, a domestic worker who is invariably deeply immersed in fantasy, appears throughout Mary Sibande's oeuvre (ranging from Long Live the Dead Queen (2009), to the series, The Purple Shall Govern $(2013,2014)$ ). Sophie is employed by the artist in order to engage with patriarchal and apartheid representations of black femininity, where it is particularly Sophie's body which registers the traumatic impact of these systems. We contend that Sibande's portrayal of Sophie, where she is continually engaged in fantasy and articulates trauma at the site of the body, is consistent with hysterical representation. Our interpretation of hysteria is derived from the feminist understanding thereof, where it is not understood as a form of pathology, but rather as a mode of representation which allows the subject to articulate repressed traumatic knowledge and repressed desire in a negotiated manner, from within the confines of an oppressive system. Hysteria is understood as involving the representation of repressed traumatic knowledge and repressed desire through fantasy and the body.
\end{abstract}

Keywords: Mary Sibande; hysteria; trauma; feminism; fantasy; repression; corporeal

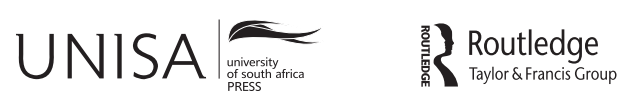

de arte

Volume 52 | Issue 2-3 | 2017 | pp. 4-28

http://doi.org/10.1080/00043389.2017.1332503

www.tandfonline.com/rdat20 


\section{Introduction}

The South African artist Mary Sibande's portrayal of Sophie, who escapes the drudgery of life as a domestic worker by means of fantasy, is intriguing. Sophie appears in a number of digital prints and installations by Sibande, ranging from Long Live the Dead Queen (2009), to the series, The Purple Shall Govern (2013, 2014). The fibreglass body of Sophie has been moulded on that of Sibande and she can be identified as the artist's alter-ego (Bidouzo-Coudray 2014). Sophie is a "quasi-fictional character" (Corrigall 2015, 146) who was developed in reference to previous generations of women in Sibande's family who had worked as domestic workers (Bidouzo-Coudray 2014). Sophie is portrayed as being deeply immersed in fantasy, and it is because she is engaged in fantasy that her domestic uniform seems to be transforming into the costume of a Victorian lady (Corrigall 2015, 147). By hybridising the clothing of a domestic worker with that of a Victorian lady, Sibande evokes the role of the mistress of the house, colonial authority, and the historical context from which domestic servitude emerges in South Africa (Corrigall 2015, 151, 152; Dodd 2010, 470-471). In this article we argue that Sibande engages with the traumatic impact of racial and patriarchal oppression on the individual and, more specifically, that in her exploration of these issues, the artist employs a strategy of hysterical representation.

Although the condition has a long history, the most extensive and acute eruption of hysteria occurs during the second half of the nineteenth century. ${ }^{1}$ The hysterical inmates of the Salpêtrière hospital (in Paris), as well as the treatments of the leading resident physician, the neuropathologist Jean-Martin Charcot, feature prominently in historical accounts of the condition (De Marneffe 1991, 72-78). In an attempt to develop a systematic method for the diagnosis thereof, Charcot compiled a history of case studies of hysteria, entitled Iconographie photographique de la Salpêtrière (1875-1880) (De Marneffe 1991, 72-78). Charcot's Iconography comprises an array of photographs and drawings representing the mostly female hysterics in the various theatrical, enigmatic and often subtly erotic postures which are characteristic of the hysterical attack. Although Charcot does point out that the malady can occasionally also afflict male patients, hysteria would continue to be regarded as generally being a female reproductive disease or be otherwise ascribed to feminine over-sensitivity in general, throughout the nineteenth century (Foucault 1965, 149; Showalter 1997, 9, 33).

Sigmund Freud's treatment of hysteria, commencing at the turn of the twentieth century, serves as a major reference influencing the manner in which the condition is envisioned today. Hysteria presents a legion of diverse and mutable symptoms, ranging from convulsions to the paralysis or contraction of limbs, and Freud $(2015,39,55,61$,

1 The term hysteria originates in ancient Greece, where the disease was considered to be an exclusively female condition, as may be inferred from the etymology of the word: hysteria is derived from the Greek word hyster (uterus) (Peters 2005, 124). Physicians ascribed the presence of the malady to the existence of a migrating womb, a sign of the female sufferer's violation of sexual and reproductive prescriptions, including that of procreation (Yarom 2005). 
$72,87)$ notes that the only constant is the fact that all symptoms manifest through the body. Freud $(2015,818)$ ascribes the variable nature of the hysterical symptomatology to the fact that symptoms do not refer to any organic cause, but have a psychical and "phantasmatic" basis. Symptoms are encrypted representations of repressed traumatic knowledge (Freud 1910, 198, 207; 1963, 258). The hysteric cannot properly verbalise her complaint, so that repressed psychical material may be articulated in a negotiated manner, by means of symptoms manifesting at the site of the body (Freud 2015, 584). The hysteric is remarkably sensitive and routinely translates "psychical excitation ... into the somatic field" (Freud 1966, 195); as Mark Micale $(1993,449)$ observes, hysteria is the paradigmatic psychosomatic condition.

Feminist scholars of the nineteen eighties revisit Freud and reclaim hysteria as a form of feminist representation (Showalter 1997, 9). ${ }^{2}$ As Cecily Devereux (2014, 20) explains: "Historically linked with femininity for hundreds of years, hysteria's involuntary, uncontrollable, somatic symptoms were coming to be understood in the emerging critical feminist discourse not as a medical condition but a cultural one, an embodied index of forms of oppression." Feminists conceive of hysteria as a peculiarly feminine form of representation, an alternative to proper verbalisation, where the body is the main vehicle for articulating that which cannot be properly articulated otherwise (Devereux 2014, 21). Charles Bernheimer and Claire Kahane (1985, 5), as well as Rhona Justice-Malloy $(1993,133)$ interpret hysteria as comprising a reaction to patriarchy, where it has failed to fully acknowledge or sanction the desires of women. Dianne Hunter (1983, 484-86) similarly indicates that hysteria is a compromised means of communication, a "form of feminist discourse in which the body signifies what social conditions make it impossible to state linguistically." According to Hunter (1983, 485-486), hysteria comprises a subtly oppositional means of expression which emerges in reaction to regulatory social conditions; Hunter correlates the prevalence of hysteria during the late nineteenth century with patriarchal repression and attributes its pervasiveness during that era to the severity of patriarchal attitudes. Hysteria is considered to be a compromised form of expression insofar as symptoms conform to the acceptable boundaries delimiting feminine behaviour. Carroll Smith-Rosenberg $(1986,1999)$ exemplifies this by referring to the behaviour of nineteenth century female

2 Feminists particularly engage with hysteria via Freud, where his encounters with the hysterical patient known by the pseudonym of Dora, are especially influential. In The Newly-Born Woman (1975) Hélène Cixous and Clement (1987, 154), viewing hysteria as a form of silent resistance, describe Dora as a feminist martyr. Dora is also the subject of Charles Bernheimer and Claire Kahane's compilation of feminist writings entitled In Dora's Case. Freud-Hysteria-Feminism (1985). Dora is the pseudonym of Ida Bauer, the patient who Freud (2015, 572-617) refers to in Fragments of an Analysis of a Case of Hysteria (1905). Dora suffered from a range of hysterical symptoms, including aphonia (an inability to speak) and a nervous cough. She was traumatised when, while she was still an adolescent, a close friend of her father, known as Herr K, made sexual advances to her. Freud argued that Dora suffered from repressed sexual desire for Herr K, as well as repressed homosexual feelings for his wife, Frau K. 
hysterics who used illness as an escape, as a socially sanctioned, oblique method of rebellion, where symptoms such as fainting were reconcilable with the prescribed norms for femininity (such as frailty and passivity).

In this article, our definition of hysteria is derived from the feminist interpretation thereof inasmuch as we do not interpret hysteria as a pathological condition. As is consistent with the feminist interpretation thereof, we understand hysteria as a mode of representation which allows the subject to articulate repressed traumatic knowledge and repressed desire from within the confines of an oppressive system. Our interpretation of hysteria diverges from the conventional feminist interpretation thereof, however, insofar as hysteria is not merely understood as comprising a reaction to patriarchy, but as potentially also comprising a negotiated reaction to other regulatory social conditions, as well. Our interpretation of hysteria is derived from Elisabeth Bronfen $(1998,40)$, where she describes hysteria as a particular mode of representation for the articulation of repressed trauma, where trauma is understood as relating not merely to patriarchal oppression, but as also encompassing other aspects. In the context of hysteria, Bronfen $(1998,20,34,35)$ employs the term "trauma" widely, and in a non-gendered manner, to refer to the subject's perception of his or her own physical vulnerability and mortality, or his or her oppression on either a socio-political or personal level. In this article, hysteria is characterised as a particular mode of representation which entails the articulation of repressed traumatic knowledge and repressed desire by means of fantasy and through the register of the body. In our interpretation of Sibande's artworks through the lens of hysteria, the trauma referred to is that of patriarchal and racial marginalisation.

An interpretation of Sibande's artworks in relation to hysteria is not wholly unprecedented. Penny Siopis has previously explored the themes of patriarchal and racial discrimination in relation to hysteria, and in the South African context, in her artwork, Dora and the Other Woman (1988). The artwork refers to Freud's hysterical patient, Ida Bauer (1882-1945), known by the pseudonym of Dora, whose desires, according to Siopis (quoted in Coombes 1997, 121) were represented by Freud as a pathology. The artwork relates Dora's history to that of Sara Baartman (1788-1816), the Khoisan woman whose body was scrutinised by both the European public and anatomists alike, according to Carole Boyce Davies $(2008,137)$, in order to form judgements regarding the sexuality of black women. As is consistent with the contemporary feminist interpretation of the condition, Siopis $(1999,248)$ locates hysteria as a response to patriarchal objectification. The painting, Dora and the Other Woman, implies that the two women share a similar experience to the extent that their sexuality has historically been represented in a demeaning manner. ${ }^{3}$

3 Siopis (in Willis 2010, 134) notes that, like Bauer, "Saartjie could be seen in some sense to represent, for all African women, a body bearing out desire"; for Siopis (in Coombes 1997, 120), Baartman symbolises the manner in which black women's sexuality has historically been interpreted in both a sexist and racist manner. 
Siopis's reference to hysteria in the South African context serves as precedent for our own analysis of Sibande's artworks. While Siopis's application of hysteria is emblematic of the late twentieth century feminist stance as well as of resistance art, we examine hysteria in the contemporary and post-apartheid milieu. ${ }^{4}$

\section{Sophie and hysteria}

The "quasi-fictional character" (Corrigall 2015, 146), Sophie, has been pervasive in Sibande's oeuvre, ranging from Long Live the Dead Queen (2009) to The Purple Shall Govern $(2013,2014)$. On the basis of the homogeneous quality of these series, these can be interpreted as forming part of a single thematic exploration and a single narrative. We aim to correlate Sibande's portrayal of Sophie throughout these series with hysterical representation, below.

\section{Fantasy}

The first characteristic of hysteria which we aim to identify as being prevalent in Sibande's portrayal of Sophie, is an indulgence in fantasy. Jean Laplanche and JeanBertrand Pontalis $(1968,1)$ define fantasy as a "term used to denote the ... the imaginary world and its contents." According to Laplanche and Pontalis (1973, 317), fantasies can be understood as comprising "scripts (scénarios) of organised scenes which are capable of dramatization - usually in a visual form"; fantasy is "a sequence in which the subject has his own part to play." According to Freud $(1963,374 ; 2015,1639)$, the hysteric frequently escapes reality by immersing herself in fantasy; this may occur to the extent that reality and unreality interpenetrate and become indistinguishable in her mind. The hysteric enjoys weaving fantastical narratives and fantasy serves as a means by which she may express repressed desire, albeit in a compromised manner (Freud 2015, 817).

The hysteric routinely makes visible her fantasies through performances. Freud $(2015,837)$ refers to these performances as the hysterical attack, where he states that "these attacks are nothing else but phantasies translated into the motor sphere, projected on to motility and portrayed in pantomime." ${ }^{5}$ During the hysterical attack or pantomime the hysteric physically performs her fantasies, so that fantasy is therefore superimposed onto reality as an "external stage" (Bronfen 1998, 155).

Fantasy it is overtly present in Sibande's artworks: Alexandra Dodd $(2009,42)$, Joyce Bidouzo-Coudray (2014), Thembinkosi Goniwe (2011, 247), Kerry Bystrom (2016), as well as Mary Corrigall $(2015,146)$ all state that Sophie is perpetually

4 The term, resistance art, refers to art which was critical of the "racial, cultural and or political policies" of the apartheid state (Towards a People's Culture, Art and Resistance under Apartheid 2016).

5 As Laplanche and Pontalis $(1973,317)$ note, the different spellings, "fantasy" and "phantasy", which are to be found in translations of Freud as well as in the secondary literature, hold no significance and can be attributed to the different translations of Freud's German word "Phantasie". 
immersed in fantasies of empowerment. ${ }^{6}$ Goniwe $(2011,247)$, for example, asserts that Sophie "embodies a set of fantasies and imagined tales that on the one hand unsettles her state of being a maid or domestic worker while on the other presents the possibility of change, of becoming something other than a subordinate servant." It is significant that these theorists interpret Sibande's artworks in terms of fantasy, as we aim to develop the notion further and locate these fantasies specifically as being characteristic of hysterical representation.

As is consistent with hysterical representation, Sophie's fantasies are made visible as actual performances. Sibande portrays Sophie as being physically engaged in the performance of several phantasmatic roles, including those of "a lady, a housewife, a religious devotee, a queen, an artist, a horse rider, a soldier and a shopper" (Maurice and Dodd 2014, 1). The Wait seems to go on Forever (2009) for example, portrays Sophie where she is engaged in fantasy, while waiting at a bus-stop. ${ }^{7}$ The artwork evokes the cumbersome commute which is part of the normal daily routine of domestic workers (who normally reside in townships far from their place of employment). Rather than being mindful of her actual situation, Sophie is portrayed as being immersed in a fantasy of luxury, as signified by the chandelier suspended overhead.

\section{Trauma}

Corrigall $(2015,146,147)$ suggests that Sophie's fantasies have a traumatic basis, where she states of Sophie:

Her eyes are always shut, setting her imagination free to dream up ensembles that could liberate her from domestic toil. Without the constraints of reality she settles on the antithesis of who she is: a royal figure from the colonial era who embodies the power and opulence absent from her everyday existence. Her garments become the site upon which she reinvents herself and maps out her evolution from domestic worker to mistress, from oppressed to oppressor. ${ }^{8}$

If Sibande's fantasies have a traumatic basis, this correlates with hysteria. The aetiology of hysteria is of an exclusively psychological nature; it is precipitated by a traumatic experience or impression (Freud 2015, 187). Freud $(2015,174)$ particularly attributes the onset of hysteria to the sufferer's experience of a shock of a sexual nature, such as a "premature sexual experience", where it may also arise out of repressed desire

6 While her analysis cannot be explored within the limitations of this article, Corrigall $(2015,146)$ provides a particularly intriguing examination of Sibande's artworks in her article, Sartorial excess in Mary Sibande's "Sophie", by analysing the artist's phantasmatic outfit in relation to dandyism, where luxurious clothing "visualises a desire for social mobility."

7 Image available at: http://umma.umich.edu/archive/view/exhibitions/2013-Sibande.php

8 As Corrigall (2009, capitalisation in original) notes, Sophie's guise as domestic worker is apt and enables Sibande to explore the politics of race: "OVEREXPLOITED and positioned within the heart of white South Africa, domestic workers have been the ultimate victims of a skewed social and political system thus their occupation embodies the vexed racial dynamics in this country." 
(Freud 1910, 206). According to Freud (1955, 34), hysterical fantasies originate in traumatic memories and are intended to mediate their traumatic content. Bronfen (1998, 37) describes fantasies as "psychical facades constructed to bar memories." Since she suffers "from incompletely abreacted psychical trauma" (Freud 1955, 34), the hysteric's fantasies do not only involve pleasurable reminiscing, but also have a traumatic undercurrent. Traces of traumatic memories pervade the hysteric's fantasies, but she is nevertheless preoccupied with the past (Freud 1955, 34, 290). Fantasy may allow the hysteric access to repressed traumatic knowledge, from which she may derive a form of traumatic enjoyment (Bronfen 1998, 149). She compulsively attempts to access repressed traumatic knowledge, through fantasy (Breuer and Freud 1955, 290; Freud 1966, 223).

Sophie's fantasies have a traumatic quality, Corrigall $(2015,146,147)$ implies. However, it is necessary to elaborate on the traumatic aspect thereof below, in order to clearly correlate Sophie's fantasies with the traumatic nature of hysterical fantasy. ${ }^{9}$ As we demonstrate, Sibande's artworks subtly refer to the traumatic impact of patriarchy, apartheid and colonialism, where these systems are often signified particularly through Sophie's attire.

Especially in her manifestations prior to The Purple Shall Govern series (2013, 2014), Sophie is shown wearing a blue dress which hybridises the contemporary uniform of a domestic worker with Victorian costume (Corrigall 2015, 147). As we have stated, the Victorian dress signifies both the role of the mistress of the house and calls to mind colonial authority (Corrigall 2015, 151, 152) so that Sophie's hybridised clothing therefore serves to evoke the historical context from which domestic servitude emerges in South Africa (Brown 2011, 77). Sophie's dress serves to evoke the racial hierarchies which originated during the colonial period and persisted into the apartheid era (Dodd 2010, 470-471); these hierarchies are examined in a critical manner, Carol Brown $(2011,77)$ adds: "She [(Sibande)] inverts the social power indexed by Victorian costume by reconfiguring it as a domestic worker's 'uniform'; problematising the colonial relationship between 'slave' and 'master' in a postapartheid context."

Sibande also refers to racial concerns by employing colour in a symbolic manner (Maurice and Dodd 2014, 5). The repetitive and restricted colour palette which she employs suggests that the hues are symbolic in nature: Sophie is clothed in blue, with details in white, or she wears purple. Colour symbolism is particularly evident in the title of the series The Purple Shall Govern, which is an overt reference to the trauma of apartheid, as it is based on an anti-apartheid slogan. As Emile Maurice and Rebecca Dodd $(2014,5)$ explain, the series title refers to the "graffiti that appeared on walls

9 While it remains an integral part of her work in our reading, we do not wish to imply that Sibande's artworks function solely in the register of trauma. As Bystrom (2016) indicates, Sibande's artworks also move beyond this and cannot be categorised as being purely post-traumatic. Sarah Nuttall (2013, 429) similarly states that Sibande succeeds in moving "away from the language of wounds" toward a form of resistance. 
around the city of Cape Town in 1989, after police sprayed protestors participating in an anti-apartheid march with purple dye. It is a play on a clause in the Freedom Charter that says 'The people shall govern'." Sibande (in Mabandu 2013) adds that purple, in the context of protest, is "a colour of privilege", stating that she is "attempting to use this privilege afforded to me by those who have fought for it." The artist also states that purple connotes royalty: "The clergy and the royalty of England wear, or wore, purple if they were meeting an important person. Purple dye was expensive so only the rich were able to wear it" (Sibande in Krouse 2013). Sibande (in Mabandu 2013) notes that she employs the colour in an ambiguous manner, stating that purple may, on the one hand, suggest governance, but that those marked by this hue are also, on the other hand, "marked to be arrested". White connotes servitude; it is almost exclusively reserved for Sophie's apron and headdress, items of clothing which are associated with domestic labour (Corrigall 2015, 150). The blue colour of her dress similarly signifies domestic labour, as this particular hue is typically used for the mass-produced uniforms worn by domestic workers or other South African labourers (Corrigall 2015, 150); on the other hand, the ultramarine hue also recalls the Virgin Mary, as the use of expensive pigment was mostly reserved for the painting of the Madonna's robes, during the Renaissance (Gage 1993, 130). Whereas the role of the domestic worker has often been denigrated, Sibande's ambiguous use of the colour blue complicates such traditional associations.

Apart from addressing race, Sibande's artworks also comprise a feminist examination of the regulatory and inhibiting impact of those expectations for femininity which have been created for women in a socio-culturally stratified and patriarchal society (Brown 2011, 77). Sibande investigates the manner in which "privileged ideals of beauty and femininity aspired to by black women discipline their body through rituals of imitation and reproduction" (Brown 2011, 77). The series engages with the "Western ideal of beauty" (Bidouzo-Coudray 2014); this is particularly overt in artworks such as Conversations with Madam CJ Walker (2008) and I put a Spell on Me (2008). ${ }^{10}$ In the former artwork, which refers to the eponymous entrepreneur who marketed hair products to the African market during the Victorian era, Sophie is shown holding strands of synthetic hair. ${ }^{11}$ In the latter artwork, the staff, which is part of the liturgical accoutrements of the Zion Christian Church, is wrapped in fabric with a Louis Vuitton design; it is suggested that the staff has inspired awe in Sophie, so that the notion of religious worship is collapsed into a consumerist myth of beauty.

10 Conversations with Madam CJ Walker can be viewed at: http://www.artcritical.com/2010/06/29/ dispatches-capetown/. The latter image is available at: http://www.anotherafrica.net/art-culture/marysibande-triumph-over-prejudice.

11 As is characteristic of Sibande's artworks, Conversations with Madam CJ Walker is ambiguous, and does not purely have negative connotations. As Bystrom (2016) notes, Madam CJ Walker was an iconic figure - a slave who later managed to become a millionaire - and Sibande's reference to her therefore also serves to signify emancipation. Bystrom (2016) supports this interpretation by referring to the fact that Sibande's own mother's work in a hair salon similarly enabled her to escape a life of domestic servitude. 
Apart from involving fantasy and possessing a traumatic basis, another feature of hysterical representation which we identify in Sibande's artworks, is an engagement specifically with primal fantasy. This traumatic form of fantasy is highly prevalent in hysteria (Freud 2015, 575, 670, 671, 1205, 1477). According to Freud $(2015,364,1278)$, primal fantasy, which includes the primal scene, castration and intrauterine fantasies, is a specific form of fantasy which is universal. ${ }^{12}$ The intrauterine fantasy is a form of primal fantasy which manifests as a memory of "existence in the womb" or may entail a fantasy relating to "the act of birth" (Freud 2015, 364). A second primal fantasy is the primal scene, which comprises a traumatic fantasy of the "observation of parental intercourse" (Freud 2015, 1471, 1472, 1481), which the subject remembers as having witnessed and interrupted, as a very young child. The castration fantasy relates to a fear of castration and is often represented in dreams or myths through images of "baldness, hair-cutting, falling out of teeth and decapitation" (Freud 2015, 347). Freud $(2015,642)$ suggests that castration fantasies are mostly suffered by boys, but that these may also to some extent affect girls.

The subject who engages in primal fantasy may feel as though he or she is occupying several contradictory positions at the same time; this mobile subject may for example feel as though he or she is simultaneously both the viewer of the scene and the one viewed (Laplanche and Pontalis 1968, 13). A primal fantasy "is characterized by the absence of subjectivization, and the subject is present in the scene," Laplanche and Pontalis $(1968,13$, italics in original) state.

Such a fluid subject position is often created in Sibande's artworks, through the use of doubling. Firstly, Sophie serves as a phantasmatic self for the artist (Corrigall 2009) and can be identified as the artist's alter-ego (Bidouzo-Coudray 2014). Secondly, Sophie is herself also conspicuously doubled in several artworks by Sibande, notably in A Reversed Retrogress, Scene 1 (2013) (Figure 1), where one version of Sophie is shown interacting with her double. Sibande (in Mabandu 2013) states that in this artwork, "the ideas of violence are insinuated and yet the violated and the violator are connected. The figures' gestures are ambiguous in being neither violent nor defensive"; because of this ambiguity the perpetrator and the victim are indistinguishable, and Sibande can identify with either or both of these Sophies. Both Sophies can serve as place-holder or avatar for Sibande, so that her subject position is fluid. The diversity of subject positions created in A Reversed Retrogress, Scene 1 is consistent with the experience of the subject immersed in primal fantasy, who often feels as though he or she is both

12 Freud $(2015,2013)$ argues that primal fantasy is derived from inherited memories, stating that primal fantasy does not only have its basis in the subject's own experiences, but may also relate to "things that were innately present in him at his birth, elements with a phylogenetic origin - an archaic heritage." Laplanche and Pontalis $(1973,331)$ reject Freud's account of primal fantasy and provide a contemporary analysis thereof, by stating: "Like collective myths, they claim to provide a representation of and a 'solution' to whatever constitutes a major enigma for the child." 
viewer and participant, as well as both protagonist and victim in the scene (Laplanche and Pontalis 1968, 13).

An interpretation of $A$ Reversed Retrogress, Scene 1 as exemplifying primal fantasy is justified by the artwork A Reversed Retrogress, Scene 2 (2013), which, as the title suggests, represents the event which follows and can be interpreted as portraying an intrauterine primal fantasy. This installation can be identified as a representation of the intrauterine primal fantasy insofar as it, firstly, represents a fantasy of parturition and, secondly, portrays a mobile subject position. A massive umbilical cord dominates the scene and seems to have both originated from Sophie's own womb, and, disturbingly, from the wall behind her; Sophie seems to be both giving birth and being born. As is the case with A Reversed Retrogress, Scene 1, a fluid subject position is, therefore, created in this second scene as well. The convoluted nature of the umbilical cord suggests that the figure may even have given birth to herself. Metaphorically, the concept of selfbirth suggests that Sophie has produced her own identity. If understood in the context of hysteria, it must be noted that such an exploration of identity is typical of hysterical fantasy, which often expresses the hysteric's desire to know who she is and where her

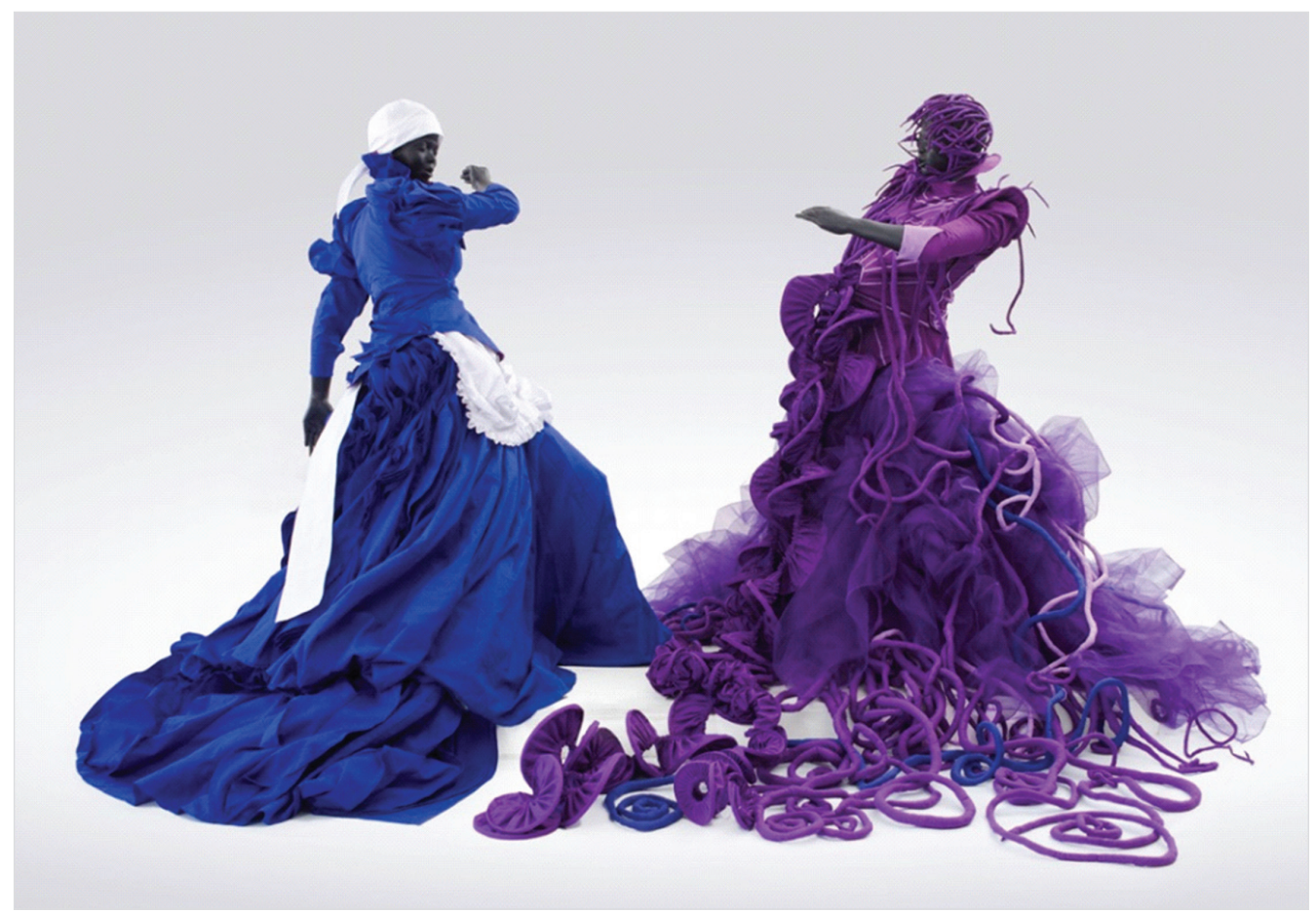

Figure 1: Mary Sibande, A Reversed Retrogress, Scene 1, The Purple Shall Govern series (2013). Mixed media installation, $1800 \times 1200 \times 1200 \mathrm{~cm}$. Photograph by A Pokroy. Image courtesy of the artist Mary Sibande and Gallery MOMO. 


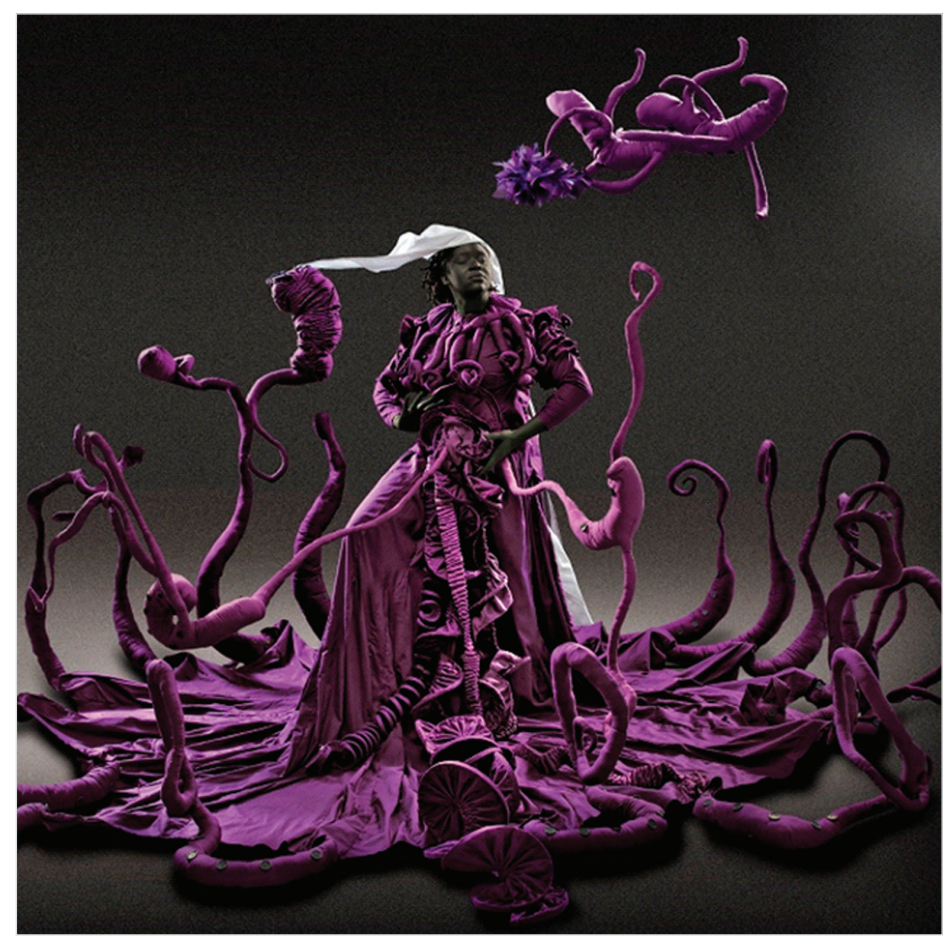

Figure 2: Mary Sibande, A Terrible Beauty, The Purple Shall Govern series (2013). Digital archival print, 111 x $113 \mathrm{~cm}$. Image courtesy of the artist Mary Sibande and Gallery MOMO.

identity originated (Lacan 1977, 168). Although the artwork is highly ambiguous and it is impossible to tell whether the figure's hands have been cast into the air in a gesture of ecstasy or despair, the artwork also evokes physical mutilation: Sibande (in Mabandu 2013) states that the figure's body has been turned inside-out. Our interpretation of the artwork as representing primal fantasy is further supported by this traumatic aspect and the oppressive atmosphere of the artwork, which is typical of primal fantasy.

Apart from portraying an intrauterine fantasy, Sibande also evokes another primal fantasy: that of castration. This is primarily signified by means of the elongated shapes which float in the air around Sophie in The Purple Shall Govern series, called "[n] on-winged ceiling beings" (Maurice and Dodd 2014, 5, 6). These shapes are highly ambiguous. In A Terrible Beauty (2013) (Figure 2), they signify Sophie's liberation, because they strip her "of the white apron and bonnet that symbolise her domestic servitude" and "appear to be looking up in admiration, vying for her attention and rejoicing at her emancipation" (Maurice and Dodd 2014, 3, 6). To this extent, because of their symbolic association with emancipation, the creatures seem to represent Sophie's desire. Their shapes simultaneously also seem to refer to foetuses or intestines, and 
seem phallic. What is more, these elongated shapes seem to have tumbled from Sophie's loins and appear to have been severed from her body. According to Bronfen $(1998,163)$, in hysteria, the castration fantasy underlies scenes where the subject imagines him- or herself as being physically mutilated. Bronfen $(1998,163)$ states that the hysterical castration fantasy may centre on mortality or on the origin of sexual difference and is often posed in order to answer the question: "Am I masculine or feminine, and how does gender relate to my body's vulnerability?" Sibande's portrayal of Sophie can be aligned with the castration fantasy in this respect: it comprises an exploration of gender relations, and in The Purple Shall Govern series, elements alluding to birth (representing the female body) are prevalent, where these are overtly juxtaposed with phallic (male) imagery. ${ }^{13}$

\section{Corporeal representation}

Thus far, Sibande's portrayal of Sophie has been aligned with hysterical representation in terms of the prevalence of fantasy therein, its association with trauma, and in terms of its engagement specifically with primal fantasy. Sibande's artworks can be further associated with hysterical representation on the basis that these evoke traumatic content in an indirect manner, through the body. It is a defining characteristic of hysteria that repressed psychical content is articulated through the register of the body; as Amanda du Preez $(2009,237,241)$ asserts, hysteria "materializes in and through the body's anatomy." Hysterical symptoms which are of psychogenic origin (articulating repressed traumatic knowledge or repressed desire) and manifest in a cryptic manner, through the body, are called conversion symptoms (Freud 1966, 195; Micale 1993, 449). An array of conversion symptoms exists and symptoms are eminently protean, often varying greatly from one patient to another. Freud $(2015,55,61)$ provides several examples thereof, including "vomiting as a substitute for moral and physical disgust"; and the "conversion of psychical excitation into physical pain."

The conversion symptom is produced through fantasy, as Lacan (1981, 164-165) explains. Insofar as fantasy is pervasive in hysteria, the hysteric produces a fantastical map of her own body; this phantasmatic map carries a great deal of weight, so that it radically skews the hysteric's perception of her own body and may wholly overwrite

13 Helene Strauss $(2014,474)$ provides an interesting analysis of the work of Zanele Muholi, the South African artist who, like Sibande, explores the themes of race and gender by using her own body. Strauss (2014, 474-476) refers to Muholi's installation What Don't You see When You Look at Me (2008), wherein a tire and a sausage feature as prominent motifs. The artist employs these motifs ambiguously: the tire evokes both the safety of the womb and "South Africa's history of resistance", and the phallic sausage refers to both the patriarchal violence (Strauss 2014, 486) which is rife in South Africa, and to intestines. In Muholi's art, ambiguity is seminal and masculine and feminine signifiers are interwoven, in order to complicate conventional gender ideas (Strauss 2014, 487). Her work therefore bears various similarities to that of Sibande and a comparison of Muholi's work with that of Sibande in this regard may prove to be productive. 
the functional body (Lacan 1981, 165). The hysteric develops compelling fantasies regarding the shape and functioning of her own body, and it is such fantasies which manifest as the conversion symptom (Grosz 1994, 40; Verhaeghe 1999, 42). The "popular visual representation of the body and its parts" (Verhaeghe 1999, 42) influences the hysteric's fantastical perception of her own body in an excessive manner, so that the symptom develops according to popular ideas regarding the functioning of the body. A typical hysterical fantasy of the body as being fragmented underlies the hysterical symptom of partial paralysis, for example, where the hysteric imagines that a part of a limb is paralysed. Elizabeth Grosz $(1990,45)$ explains how the hysteric's phantasmatic anatomy may produce this latter symptom:

Hysterical paralyses show a "logic" that relates more to the body's visible form than its biological makeup. An arm that is hysterically paralysed will, in all likelihood, be paralysed from a jointshoulder, elbow, or wrist - rather than from muscular groupings as would occur in the case of physical injury.

The conversion symptom is highly enigmatic, insofar as it represents repressed psychical material in a cryptic manner. Apart from the fact that such a symptom encrypts perturbing psychical material somatically, it also articulates repressed thoughts in an inherently distorted manner (Freud 1910, 184, 202; 2015, 202-209, 837). Lacan (1977, 166) describes the process by which disturbing thoughts and memories are converted into something unrecognisable during symptom-formation as being largely metaphorical, where the hysterical conversion symptom is conceived of as an embodied metaphor:

Between the enigmatic signifier of the sexual trauma and the term that is substituted for it in an actual signifying chain there passes the spark that fixes in a symptom the signification inaccessible to the conscious subject in which that symptom may be-a symptom being a metaphor in which flesh or function is taken as a signifying element.

Elaine Showalter $(1997,54,55)$ illustrates the metaphorical aspect of the conversion symptom, by stating:

Nineteenth-century hysterical women suffered from the lack of a public voice to articulate their economic and sexual oppression, and their symptoms - mutism, paralysis, self-starvation, spasmodic seizures - seemed like bodily metaphors for the silence, immobility, denial of appetite, and hyperfemininity imposed on them by their societies.

In Sibande's artworks, metaphor is often employed in order to subtly evoke trauma. The elongated shapes which frequently emerge from Sophie's dress are notable in this regard. These seem phallic, and sometimes the coils unfurling from her body recall intestines; as these shapes have been severed from her body, these evoke bodily trauma in the form of castration or evisceration, respectively. The evisceration and castration of Sophie do not seem to represent real events and can be interpreted as being metaphors of trauma. In the context of Sibande's examination of the traumatic impact of patriarchy, colonialism and apartheid, it can be assumed that these two tropes (evisceration and 
castration) refer to the traumatic impact of these systems on the individual. Brown (2011, 77) highlights that the physical representation of trauma is pervasive in Sibande's series, stating that the artist uses Sophie's body "as a site where history is contested." Insofar as the metaphors which Sibande employs in order to represent traumatic impact are represented at the site of Sophie's body, these are analogous to the hysterical conversion symptom. The conversion symptom is produced precisely by such a transformation of traumatic psychical impressions into physical form (Breuer and Freud 2015, 37), where Lacan $(1977,166)$ defines the symptom as a corporeal metaphor where "flesh ... is taken as a signifying element."

\section{Mimicry}

Apart from an indulgence in fantasy, primal fantasy and the corporeal and cryptic representation of repressed traumatic knowledge, a further characteristic of hysterical representation which we identify in Sibande's artworks is the subject's mimetic engagement with the very system which has traumatised her.

The hysteric is highly impressionable and symptoms such as pantomime are often mimetic in nature, so that her performances frequently conform to those images and roles which are prescribed for her by others. This is exemplified by the nineteenth century hysterical inmates of the Salpêtrière, who would comply extravagantly and on demand with their physicians' commands for the demonstration of symptoms. Resident physicians would regularly provoke hysterical attacks and demonstrations from patients by employing hypnosis, to be performed for the benefit not only of interested members of the medical community, but also for members of the public (Showalter 1985, 35, 149). These performances were generally spectacular in nature and drew crowds of spectators. However, the hysterics' compliance was excessive and, as Elaine Showalter $(1985,149)$ points out, the postures which the women adopted were uncannily similar to those represented in the images hanging from the walls of the hospital's demonstration hall, which depicted hysterical attacks. ${ }^{14}$

As Showalter $(1985,149)$ explains, hysterics' symptoms are often developed to conform to an existing iconography of hysteria. The fantasies which the hysteric performs frequently seem to mimic the fantasies of those around her; the hysteric seems to fulfil those expectations and mime those representations which have been provided for her. Moreover, because the hysteric's fantasies develop in response to her milieu, her symptoms vary and are assimilated to the existing socio-historical context (Veith 1965, 209). The hysteric's mimetic performances are further characterised by theatricality,

14 One such artwork is a lithograph of Pierre Aristide André Brouillet's painting, A Clinical Lesson at the Salpetrière (1887), where Charcot is portrayed holding a woman who has succumbed to a hysterical attack. Two other artworks also lined the walls: Dr Philippe Pinel at the Salpetrière (1795), by Tony Robert-Fleury, which depicted the physician amongst the women housed in the asylum; and Paul Richer's Arc de Cercle (1887), a graphic image depicting a particular phase in a hysterical episode (Showalter 1985, 149). 
where the hysteric has an unparalleled ability to perform various roles and assume various identities in quick succession; Showalter $(1997,102)$ refers to the trope of "the hysterical woman as actress." 15 Vicki Kirby $(1997,57)$ refers to the hysteric's "chameleon display", adding: "It is as if the hysteric is a mirror of her surroundings." The famous Salpêtrière hysteric known as Augustine, for example, simulated postures borrowed from a whole range of cultural narratives. Many of her fantasies seemed to be derived from the media, as Bronfen $(1998,196)$ points out: "Her simulation is compiled like a patchwork of an array of narratives taken from romance plots-gestures mimicking the iconography of visual representations of possession with modes of theatrical acting popular at the time."

Mimicry can be identified in Sibande's artworks, where she engages mimetically with patriarchal and apartheid representations of black femininity. While several of her artworks, including Conversations with Madam CJ Walker, engage with Western and patriarchal ideals for feminine beauty, Sibande does not examine these in a manner which is overtly critical. Rather, Sophie generally seems to comply with patriarchal ideals: firstly, Sophie is represented as a mannequin (Corrigall 2015, 147), which inherently presents an ideal physical form for women to aspire to (an ideal provided for women in the patriarchal paradigm); secondly, the anachronistic Victorian dress, with its corsetry, cumbersome undergarments and prodigious size (which Sibande further lengthens and exaggerates) radically restricts movement, and connotes the contemporaneous patriarchal expectation that women will be passive and modest, as Sibande suggests (in Balboa-Pöysti 2011); furthermore, Sophie is portrayed as being quietly engaged with some of the select few occupations which were deemed feminine in the patriarchal Victorian context, and in a manner which suggests contentment. ${ }^{16} \mathrm{In}$ They Don't Make Them Like They Used To (2008), Sophie is shown knitting, and she is portrayed as being immersed in tapestry or embroidery in Wish You Were Here (2010); Conversations with Madam CJ Walker portrays Sophie as being serenely occupied with the grooming of hair.

Sibande's mimetic performances accord with the patriarchal representation of femininity, a feature which is eminently typical of hysteria. Insofar as hysteria has been deemed a woman's disease and has been strongly associated with femininity, the hysteric's mimetic fantasies often correspond to patriarchal cultural representations and expectations regarding femininity (Showalter 1997, 9, 64; Foucault 1965, 149). Symptoms are frequently adjusted to correspond to culturally acceptable expressions

15 While Freud $(2015,817)$ asserts that the hysterical pantomime is not a conscious production but rather refers to it as being "involuntary", Showalter's $(1985,149)$ analysis thereof suggests that a conscious element may also have been involved.

16 Sibande's work is layered with meaning. Nuttall $(2013,429)$ provides an interesting interpretation of Sibande's use of the mannequin, where she argues that the plastic skin of the mannequin is employed figuratively. Whereas the wounded black female body has routinely been used in feminist culture to serve as reminder of trauma of racial oppression, the polished plastic skin of Sophie-as-mannequin seems impervious, and, as such, suggests a resistance to suffering (Nuttall 2013, 428, 429). 
of feminine distress, according to "the prevailing concept of the feminine ideal" (Veith 1965, 209).

The mimetic nature of Sibande's fantasies should, however, not be understood as signifying a wholesale compliance with patriarchal ideals. In the late twentieth century, the French feminist, Luce Irigaray, recuperates the mimetic quality of hysteria as a potentially empowering feminist strategy. Irigaray $(1985,142)$ argues that the cultural realm has been dominated by patriarchy and that hysterical mimicry comprises the sole means of expression available to women, who have been excluded from participation in culture. The only recourse available to women who wish to represent themselves, is to mimetically appropriate those representations which have been provided for them within the existing (patriarchal) system of representation. Those representations which have been constructed for women in the existing patriarchal paradigm are appropriated and repeated; this makes it possible for women to engage with and question these very roles, as Irigaray $(1985,76)$ clarifies:

To play with mimesis is thus, for a woman, to try to recover the place of her exploitation by discourse, without allowing herself to simply be reduced to it. It means to resubmit herself ... to "ideas", in particular ideas about herself, that are elaborated in/by masculine logic, but so as to make "visible", by an effect of playful repetition, what was supposed to remain invisible: the cover-up of a possible operation of the feminine in language. It also means to "unveil" the fact that, if women are such good mimics, it is because they are not simply reabsorbed into this function.

Sophie does not only seem to be mimicking patriarchal representations of ideal femininity; Sibande's portrayal of race is comparable, insofar as Sophie seems to mimic the type of role which was often prescribed for black women during the apartheid era: that of domestic worker. While Sibande explores several phantasmatic identities which are potentially empowering insofar as these promise release from "domestic toil" (Corrigall 2015, 146, 147), including the roles of "a lady ... a queen, an artist, a horse rider, a soldier" it is significant that Sophie also performs the role of domestic worker. Sophie herself must be understood as being a fantasy on the part of the artist and, as Corrigall (2009) notes, "in dressing as a domestic worker, Sibande herself is living out a 'fantasy' of sorts."

If Sophie is to be understood as performing a fantasy on the part of the artist, this assumption of the guise of domestic servant does not immediately make sense. Corrigall (2009) points out: "Given its undesirability and the low status it signifies in our society, the domestic worker seems an unlikely figure to aspire to be." Corrigall (2009) explains Sibande's apparently paradoxical assumption of the guise of domestic worker by stating that this fantasy is a vehicle which allows her to freely explore a complex and emotionally laden subject, namely, the "politics of Self and Other." According to Corrigall (2009) (where she refers to the various appearances of Sophie as domestic worker): "Their theatrical quality confidently roots them in the realm of fantasy, thus obviating those predictable knee-jerk emotional responses which ultimately have a 
didactic goal and underscore the domestic workers' role as victim." Corrigall (2009) further adds in relation to Sibande's "domestic fantasy":

... the domestic worker is a mask, like any other she can slip on and off at will. The ease with which she is able to do this implies that no one is defined by their appearance. In assuming the guise of this highly politicised character, Sibande is able to explore, ridicule and subvert the structures that victimised the domestic worker.

Corrigall's correlation of Sophie's portrayal of a domestic worker with the donning of a mask is significant. When considering this guise, it should be remembered that it is a phantasmatic performance and Sibande does not engage with the role in an authentic manner. Rather, Sibande's artworks are highly theatrical in nature and underscore pretence. Artifice is intimated by the highly theatrical quality of the series, as Brown $(2011,77)$ notes in relation to Sibande's digital prints: "The background of all her photographs is a neutral pale shade, denoting a photographic studio setting - the ideal environment where identities can be remolded with the aid of lighting, costume, and make-up." Maurice and Dodd $(2014,1)$ explicitly compare Sophie to an actor in a play and state that she always assumes a "dramatic pose". While she may consistently don the habit of a domestic worker, Sophie also does not merely assume one identity; the roles she plays are diverse, which further implies artifice. Sophie's guise as domestic worker, Corrigall (2009) suggests, comprises a mimetic performance, which allows the artist to "explore, ridicule and subvert" this role.

Sophie's theatricality as well as her phantasmatic performance of the interpellating system's fantasies for her-where she apparently complies with the desires of the traumatising patriarchal and apartheid systems - is consistent with the mimetic behaviour of the hysteric. ${ }^{17}$ The hysteric's phantasmatic performances, like those of Sibande, often mirror the desires and representations provided for her by the particular oppressive system and it is often the desires of those who have traumatised her, which she represents in fantasy. However, it is important to note that the highly artificial nature of Sibande's mimetic performances allows the artist to evoke a gap between herself and her self-representations; this too, is an eminently hysterical strategy. As Bronfen $(1998,418)$ explains, when a mimetic performance is excessive, it allows the hysteric to suggest that those representations of her identity which have marginalised her, are inadequate, so that her mimetic self-representation "demarcates the blind spot [pointing to] that which lies outside any categorization."

17 We employ the term interpellation in an Althusserian sense. The term was coined by the Marxist philosopher Louis Althusser $(1971,11)$ in order to describe the manner in which ideology addresses the individual. 


\section{Omphalic representation}

We aim to correlate Sophie's performances with hysteria in a further respect: in terms of their omphalic nature. Bronfen $(1998,39)$ identifies omphalic representation as a defining characteristic of hysteria. She emphasises that the hysteric's mimetic performances are fraught with disturbing ambiguity and it is this ambiguity which she characterises as omphalic (Bronfen 1998, 39):

... the hysteric produces a versatile and seemingly infinite array of self-presentations, alternating between sustaining and interrogating paternal desire ... the inconsistent number of masks she dons actually displays the inconsistency of the symbolic system ruled by the paternal ... Moving seamlessly from seductive obedience to calculated derision and insolence, [she is] manipulating the masks ...

Bronfen $(1998,20,37,39)$ employs the term omphalic representation to refer to this dual quality of the mimetic hysterical fantasy, where it vacillates between "sustaining and interrogating paternal desire." The term "omphalic" is derived from the Greek word, omphalos, which means navel. Bronfen $(1998,37)$ employs the navel as a trope representing the cryptic structure of the hysterical symptom: "Like the navel, the symptom articulates an incision without allowing penetration of the wound lying beneath the knotted scar they construct." The symptom is analogous to the navel, insofar as it simultaneously points to and conceals trauma. The defining feature of omphalic signification, according to Bronfen $(1998,20,59)$, is this "counterdirectional" quality: it both veils and evokes underlying trauma.

The omphalic structure of hysterical fantasy can be illustrated by referring to the hysteric's relation to patriarchy; as stated previously, hysteria often comprises a reaction to the traumatic impact of patriarchy, although other traumatising systems may also be relevant (Bronfen 1998, 40). On the one hand, the hysteric's pantomimed fantasies mime and seem to comply with those roles which the traumatising and interpellating patriarchal system has prescribed for her (Bronfen 1998, 20, 39-44, 160-162). On the other hand, it is characteristic of omphalic representation that such mimetic fantasies are always attended by an oppositional aspect, which disrupts the illusion of compliance. Bronfen (1998, xiv, 20, 84-86) refers to the former quality, where the hysteric mimes those roles which have been prescribed for her by patriarchy, as sublimatory; by contrast, that aspect of hysterical fantasy which disrupts it, is referred to as being desublimatory. ${ }^{18}$ The sublimatory fantasy represses and protects the hysteric from having to confront traumatic knowledge; the hysteric attempts "to support the desire of his interpellating

18 Freud $(2015,588)$ defines sublimation as the process whereby the libido is deflected toward more socially desirable purposes. Bronfen's $(1998,20,84-86)$ definition of sublimation is an adaptation of its conventional meaning; in her framework, sublimation refers to a process whereby traumatic knowledge and traumatic enjoyment is repressed. Her association of sublimation with repression therefore resonates with Freud's definition of sublimation insofar as both interpretations involve the moderation of the libido. 
Other precisely because he hopes to exchange memory traces of vulnerability for a protective fiction of plenitude" (Bronfen 1998, 44). The sublimatory and mimetic fantasy also contains an oppositional element, however, as the hysteric compulsively returns to and attempts to evoke repressed knowledge (Bronfen 1998, 20, 39). Desublimation erupts as a result of the fact that the hysteric does not manage to perfectly repress her own desires or traumatic knowledge.

Contemporary artworks which employ hysterical representation often engage mimetically with the image repertoire for femininity provided by the interpellating patriarchal system; such a mimicry of ideal femininity exemplifies the sublimatory aspect of omphalic representation. However, the omphalic nature of a hysterical representation implies that it possesses a dual nature, and will involve both the "bodily imitation of culture and an expression of discontent with it" (Bronfen 1998, 413, 423, italics added). An omphalic (hysterical) representation will therefore simultaneously sustain and disturb the patriarchal code for femininity. It is a typical omphalic strategy to articulate "traumatic knowledge of somatic and symbolic vulnerability" by utilising "the body to repeat by representation an earlier traumatic impression [employing] mimetic self-representation" (Bronfen 1998, 422-427).

Traumatic knowledge is often articulated in the desublimatory hysterical fantasy in the form of scenes of horror. Specifically, as hysteria centres on the body, it is particularly the mutilated hysterical body which functions to stage the "encroachment of trauma" (Bronfen 1998, 162, 169). A desublimatory "horror" fantasy may therefore entail the portrayal of the idealised (sublimatory) female body as having been disfigured or fragmented (Bronfen 1998, 417). Contemporary hysterics employ the motif of the fragmented or horrific body in order to evoke psychic disturbance (Bronfen 1998, 34, 382). The castration fantasy is a typical desublimatory fantasy (Bronfen 1998, 162, 169). The desublimation which attends the hysteric's mimetic performances occurs when such an artist "reveals the vulnerable body and monstrous inherent in any aesthetically coherent image, occluded by sublimation" (Bronfen 1998, 429).

It is, therefore, typical of omphalic representation that the perfect and intact body should be intermeshed with the monstrous; the body is often represented as being "both healthy, and integrated, as well as diseased, and disintegrating" (Bronfen 1998, 382, italics in original). As is typical of hysterical representation, the dual quality of omphalic representation allows the artist to articulate a "discrepancy between the way someone presents him- or herself to others and how he or she really is" (Bronfen 1998, 382).

Sibande's representations of Sophie can be aligned with omphalic representation, we argue; her artworks possess a counterdirectional quality, insofar as these serve to both veil and evoke trauma. This counterdirectional quality can be identified as being inherent in the manner in which Sophie appears to transform over the course of the series. There is marked difference between Sophie's early manifestation as a domestic worker, where she is clothed in blue (in Long Live the Dead Queen, for instance), and her later appearance in The Purple Shall Govern, where she is clad in purple and her 


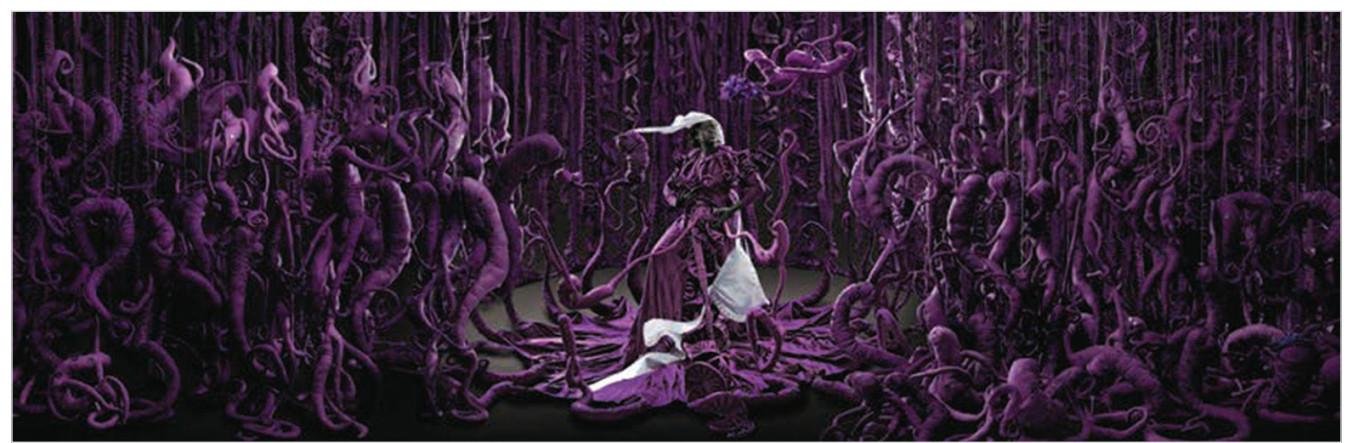

Figure 3: Mary Sibande, A Terrible Beauty is Born, The Purple Shall Govern series (2013). Digital archival print, $110 \times 320 \mathrm{~cm}$. Photograph by J Potgieter. Image courtesy of the artist Mary Sibande and Gallery MOMO.

outfit is barely identifiable as that of a domestic worker. The transformation of Sophie is overtly visible in A Reversed Retrogress, Scene 1, where the two manifestations of Sophie are juxtaposed. Sophie's transformation is so marked that Maurice and Dodd $(2014,2)$ refer to an "old" and a "new" Sophie and Tim Leibbrandt (2014) distinguishes between the new and "terrible" or "[e]vil Sophie" and the old, "Good Sophie."19

Sophie's change from "old" to "new" is made visible through her body-dress. ${ }^{20}$ The waist of the early "good" Sophie is cinched, and is presumably girdled by the obligatory corset, connoting her subscription to the patriarchal Victorian ideal of feminine beauty; Sophie is also neatly clothed in a headscarf and apron, insignia of her servitude, so that she conforms to the apartheid representation of black femininity. However, her dress and the ribbons of her apron start to take on ridiculous lengths in some artworks, for example in Silent Symphony (2010), where Sophie, who is still clad in the blue fabric of the domestic worker, indulges in the fantasy that she is conducting an orchestra. The lengths of redundant fabric become excessive in the dress of the "evil" and emancipated purple Sophie who appears in The Purple Shall Govern. In this series her waist is no longer constricted, the contents of her stomach no longer constrained, and her dress becomes monstrous; the contents of her loins tumble out and her body-dress transforms into the looming non-winged ceiling beings (A Terrible Beauty is Born, 2013) (3). The transformation of Sophie's body-dress into something horrible culminates in The Allegory of Growth (2014), where her body is infested by teeming tentacles which seem to have both inflicted a mortal wound and suffocated her.

19 Leibbrandt (2014) describes Sophie as "terrible" on the basis of the title of one of the works in The Purple Shall Govern series, namely, A Terrible Beauty.

20 In The Purple Shall Govern the dress-like tendrils of flesh unfurl from Sophie's body in such a manner that flesh and fabric become indistinguishable. Flesh and fabric interpenetrate to the extent that these can be referred to as comprising a body-dress. 
Sophie's transformation from old to new, as signified by her body-dress, correlates directly with her transformation into an emancipated figure. The Sophie who complies with repressive ideals is clothed in a blue dress of a relatively modest length; by contrast, the dress of the Sophie who contravenes these ideals by being emancipated is purple, loosened and excessively lengthened, eventually becoming horrific. The dissent of the "terrible" Sophie, who defies the restrictive patriarchal and apartheid systems, is therefore represented through the portrayal of physical release. This release involves an actual release from confining garments (signifiers of oppression), a process continued by the motif of her unfurling and widening dress and her body's ultimate dehiscence and division into the non-winged ceiling beings which represent her desire.

The fantasies of early Sophie, insofar as these seem to represent a desire to fulfil those roles which the interpellating patriarchal and apartheid systems have prescribed for her, are emblematic of the sublimatory form of hysterical fantasy. However, as is consistent with the counterdirectional (omphalic) nature of hysterical fantasy, Sibande also portrays the inverse, a desublimatory fantasy, where this is articulated by means of a mutilated body. Sophie's body-dress is suggestive of bodily mutilation, so that emancipation is signified by means of an aesthetic of physical horror. This quality - of "corporeality gone awry" (Bronfen 1998, 38) - is a feature which is closely associated with hysteria, and the representation of the body as horror is typical particularly of the contemporary hysteric. Hysteria "hooks to the body its message of the return of [the] repressed." Bronfen $(1998,41,382)$ states: "Such fantasies of the subject's own physical mutilation are highly emblematic of the desublimatory form of fantasy which performs the eruption of repressed traumatic knowledge."

In this omphalic context, understood as a sublimatory fantasy, it seems that "good" Sophie must represent repression; that is, repression of the traumatic knowledge of her own unrepresentable desire. By contrast, "terrible" Sophie confronts and stages this traumatic knowledge. The eruption of the desire of the "new" Sophie is signified by the presence of the non-winged ceiling beings, and it is this aspect, along with the horrible aspect of her mutilated body, which serves to evoke the repressed.

\section{Conclusion}

To conclude, we have identified the following features of Sibande's artworks as significant: her portrayal of Sophie as being engaged in fantasy, including the traumatic primal fantasies of intrauterine existence and castration; the articulation of psychic trauma at the register of the body; the manner in which Sibande engages with traumatising apartheid and patriarchal representations of black femininity by means of mimicry; and her omphalic engagement with these roles, where she seems to simultaneously comply with and subvert these representations, notably through the depiction of bodily horror. These are all features which are highly characteristic of hysteria, and therefore serve to establish that Sibande's artworks are emblematic of hysterical representation. 
It has been demonstrated that Sibande leverages a strategy of hysterical mimicry in order to evoke a gap between herself and the various roles which have been prescribed for her in the apartheid-colonial and patriarchal systems. As Hunter (1983) has asserted, hysteria serves as a negotiated means of communication, which functions from within the limitations of an oppressive system, to allow the subject to evoke repressed desire as well as repressed traumatic knowledge. Sibande's use of a hysterical strategy is therefore significant, as it enables the artist to engage directly with marginalising patriarchal and apartheid-colonial representations, only to disturb or disrupt these. Omphalic hysterical representation enables Sibande to not only evoke the trauma of racial and patriarchal oppression, but also allows her-simultaneously — to articulate her dissent.

\section{Acknowledgement}

The financial assistance of the National Research Foundation towards the completion of this research is hereby gratefully acknowledged.

\section{References}

Althusser, L. 1971. Lenin and philosophy and other essays. London: Verso.

Balboa-Pöysti, R. 2011. "Mary Sibande: Dressed to tell South Africa's Tale. [O]." https://ruxandrabp.wordpress.com/2011/11/25/mary-sibande-dressed-to-tell-south-africas-tale/ (accessed 2 August 2015).

Bernheimer, C., and Kahane, C. (eds). 1985. In Dora's Case. Freud-Hysteria-Feminism. New York: Columbia University.

Bidouzo-Coudray, J. 2014. "Mary Sibande_poking at Power Relations in Post-Apartheid South Africa." The Guardian. http://www.theguardian.com/world/2014/jan/07/mary-sibande-south-africa-Art (accessed January 2016).

Boyce Davies, C. E. (ed.). 2008. Encyclopedia of the African Diaspora: Origins, Experiences, and Culture. Santa Barbara: ABC-CLIO.

Breuer J., and Freud, S. 1955. Studies on Hysteria. Standard edition, Volume II. Trans. J. Strachey. New York: Basic books.

Breuer, J., and Freud, S. 2015. "Studies on Hysteria." In Complete Works. 1890-1939: 5-130. http:// staferla.free.fr/Freud/Freud\%20complete\%20Works.pdf (accessed 14 May 2015).

Bronfen, E. 1998. The Knotted Subject. Hysteria and its Discontents. Princeton: Princeton.

Brown, C. 2011. "Recent Acquisitions at two South African Collections: UNISA and Durban Art Gallery." African Arts (Autumn): 76-83.

Bystrom, K. 2016. Democracy at Home in South Africa: Family Fictions and Transitional Culture. New York: Palgrave Macmillan. 
Cixous, H., and Clément, C. 1987. The Newly-Born Woman. Minneapolis: University of Minnesota.

Coombes, A. E. 1997. "Gender, 'Race', Ethnicity in Art Practice in Post-Apartheid South Africa: Annie E. Coombes and Penny Siopis in Conversation.” Feminist Review, 55 (Consuming Cultures), Spring: $110-129$.

Corrigall, M. 2009. "Mary Sibande: Domestic Fantasy." In Incorrigible Corrigall. Mary Corrigall's indepth Commentary on Art. http://corrigall.blogspot.co.za/2009/08/mary-sibande-domestic-fantasy. html (accessed 4 February 2015).

Corrigall, M. 2015. "Sartorial Excess in Mary Sibande's 'Sophie'." Critical Arts: A South-North Journal of Cultural and Media Studies 29 (2), April: 146-164.

De Marneffe, D. 1991. "Looking and Listening: The Construction of Clinical Knowledge in Charcot and Freud.” Signs 17 (1): 71-111.

Devereux, C. 2014. "Hysteria, Feminism, and Gender Revisited: The Case of the Second Wave." English Studies in Canada 40 (1), March: 19-45.

Dodd, A. 2009. “There's something about Mary.” Elle Decoration 64 (Spring): 42. http://elledecoration. co.za/profiles/artists/ (accessed 12 June 2016).

Dodd, A. 2010. "Dressed to Thrill: The Victorian Postmodern and Counter-Archival Imaginings in the Work of Mary Sibande." Critical Arts: A South-North Journal of Cultural and Media Studies 24 (3): $467-474$.

Du Preez, A. 2009. "For Real: Hysteria, Transsexuality and Femininity-as-Masquerade." In Taking a Hard Look: Gender and Visual Culture, edited by A du Preez. Newcastle: Cambridge scholars, 237-252.

Foucault, M. 1965. Madness and Civilization. A History of Insanity in the Age of Reason, second edition. New York: Random House.

Freud, S. 1910. "The Origin and Development of Psychoanalysis." The American Journal of Psychology 21 (2), April: 181-218.

Freud, S. 1955. "The Psychotherapy of Hysteria." In Studies on Hysteria, Standard edition, Volume II, by J. Breuer and S. Freud. Trans. J. Strachey. London: Hogarth, 253-307.

Freud, S. 1963. Introductory Lectures on Psycho-Analysis, Standard edition. Volume 16. Trans. J. Strachey. London: Hogarth.

Freud, S. 1966. Extracts from the Fliess Papers, Standard edition, Volume 1, third edition. Trans. J. Strachey. London: Hogarth.

Freud, S. 2015. Complete Works. 1890-1939. http://staferla.free.fr/Freud/Freud\%20complete\%20Works. pdf (accessed 14 May 2015).

Gage, J. 1993. Color and Culture: Practice and Meaning from Antiquity to Abstraction. Berkeley: University of California. 
Goniwe, T. 2011. "Exhibition preview. Desire: Ideal narratives in contemporary South African art. South Africa's exhibition at the Venice Biennale, 4 June-27 November." African Identities 9 (2), May: $247-248$.

Grosz, E. 1990. Jacques Lacan: A Feminist Introduction. Routledge: Abingdon.

Grosz, E. 1994. Volatile Bodies: Toward a Corporeal Feminism. Bloomington: Indiana.

Hunter, D. 1983. "Hysteria, Psychoanalysis and Feminism: The Case of Anna O." Feminist Studies 9 (3), Fall: 465-488.

Irigaray, L. 1985. Speculum of the Other Woman, second edition. Ithaca: Cornell.

Justice-Malloy, R. 1993. "Charcot and the Theatre of Hysteria." Journal of Popular Culture 27 (4): 133138.

Kirby, V. 1997. Telling Flesh. The Substance of the Corporeal. New York: Routledge.

Krouse, M. 2013. "Mary Sibande: The Purple shall reign at Grahamstown's Arts Fest." Mail \& Guardian. http://mg.co.za/article/2013-06-21-mary-sibande-the-purple-shall-reign-at-the-fest (accessed 16 May 2014).

Lacan, J. 1977. Écrits: A Selection. Trans. A. Sheridan. London: Tavistock.

Lacan, J. 1981. Four Fundamental Concepts of Psychoanalysis, edited by J. A. Miller. Trans. A. Sheridan. New York: Norton.

Laplanche, J., and Pontalis, J. B. 1968. "Fantasy and the Origins of Sexuality." The International Journal of Psycho-Analysis 49 (1): 1-18.

Laplanche, J., and Pontalis, J. B. 1973. The Language of Psycho-Analysis. Trans. D. Nicholson-Smith. London: The Hogarth Press.

Leibbrandt, T. 2014. The Purple Shall Govern by Mary Sibande at Iziko South African National Gallery. Artthrob Contemporary Art in South Africa 27 November - 15 January. http://www.artthrob.co.za/ Reviews/Tim_Leibbrandt_reviews_The_Purple_Shall_Govern_by_Mary_Sibande_at_Iziko_South_ African_National_Gallery.aspx (accessed 29 February 2016).

Mabandu, P. 2013. "The interview-Mary Sibande: Purple shall govern." City Press 7 July. http://www. news24.com/Archives/City-Press/The-Interview-Mary-Sibande-Purple-shall-govern-20150430 (accessed 9 August 2014).

Maurice, E., and Dodd, R. 2014. "A Learner Resource on the Art of Mary Sibande.” Standard Bank Gallery Learner Series 3. http://www.standardbankarts.co.za/media/3567902/172505_m_sibande_ed_supspreads.pdf (accessed 15 March 2015).

Micale, M. S. 1993. "On the 'disappearance' of Hysteria: A Study in the Clinical Deconstruction of a Diagnosis.” Isis 84 (3), September: 496-526.

Nuttall, S. 2013. "Wound, Surface, Skin.” Cultural Studies 27 (3): 418-437. 
Peters, F. 2005. "Desire-less-ness." In Genealogies of Identity: Interdisciplinary Readings on Sex and Sexuality, edited by M. Breen and F. Peters. Amsterdam: Rodopi,123-137.

Showalter, E. 1985. The Female Malady. Women, Madness, and English Culture, 1830-1980. New York: Pantheon.

Showalter, E. 1997. Hystories, Hysterical Epidemics and Modern Culture. London: Picador.

Siopis, P. 1999. "Dissenting Detail: Another Story of Art and Politics in South Africa." In Grey Areas: Representation, Identity and Politics in Contemporary South African Art, edited by B. Atkinson and C. Breitz. Johannesburg: Chalkham Hill, 245-266.

Smith-Rosenberg, C. 1986. Disorderly Conduct: Visions of Gender in Victorian America. New York: Oxford University.

Strauss, H. 2014. "Spectacles of Promise and Disappointment: Political Emotion and Quotidian Aesthetics in Video Installations by Berni Searle and Zanele Muholi.” Safundi 15 (4): 471-495.

Towards a People's Culture, Art and Resistance under Apartheid. 2016. South African History online. http:// www.sahistory.org.za/topic/towards-peoples-culture-art-and-resistance-under-apartheid (accessed 18 December 2016).

Veith, I. 1965. Hysteria. The History of a Disease. Chicago: University of Chicago.

Verhaeghe, P. 1999. Does the Woman exist? From Freud's Hysteric to Lacan's Feminine. Trans. M du Ry, Second edition. New York: Other Press.

Yarom, N. 2005. The Matrix of Hysteria. Psychoanalysis of the Struggle between the Sexes as enacted in the Body. New York: Routledge. 